\title{
5-HYDROXYTRYPTAMINE AND SKELETON STATUS
}

\author{
MD, PhD, Assistant Professor, Mara Carsote ${ }^{1}$, MD, PhD, \\ Assistant Professor, Dan Nicolae Paduraru², MD, PhD, Lecturer Adriana Elena Nica², MD, PhD, \\ Lecturer Ana Valea ${ }^{3}, \mathrm{MD}, \mathrm{PhD}$, Associate Professor Adina Ghemigian ${ }^{1}$ \\ 1 "Carol Davila" University of Medicine and Pharmacy, \\ "C.I. Parhon" National Institute of Endocrinology, Bucharest \\ ${ }^{2}$ University Emergency Hospital, "Carol Davila” University of Medicine and Pharmacy, Bucharest \\ ${ }^{3}$ Clinical County Hospital, "Iuliu Hatieganu” University of Medicine and Pharmacy, Cluj-Napoca
}

\begin{abstract}
Introduction. 5-hydroxytryptamin (serotonin) represents a monoamine with different functions. Central neurotransmitter is related to mood, food and energy regulation and indirect positive effects on bone mass via leptin and sympathetic system. Gut-derived 5-hydroxytryptamine directly influences the skeleton through Wnt/Lrp5/beta catenin signalling with opposite actions to the central pool.

Method. This is a mini-review regarding serotonin- related bone changes.

Results and discussions. All the bone cells have receptors for 5-hydroxytryptamine while skeleton may have an intrinsic ability to locally generate it. The monoamine displays paracrine and autocrine actions, some incompletely described. One practical point is the potential bone loss in clinical situations with serotonin excess, as seen in carcinoid syndrome. Up to this moment, non-bone metastatic neuroendocrine tumours are not listed as a cause of secondary osteoporosis. Another practical aspect is the use of circulating 5-hydroxytryptamine as bone turnover marker surrogate for assessing the future fragility fracture probability. Despite some correlations with classical bone remodelling markers, no clear cut conclusion has been established yet. Conclusion. 5-hydroxytryptamine displays complex effects on skeleton status, whether direct, indirect or local, but there are data still unknown, thus future need to connect the dots in this particular inter-disciplinary field.
\end{abstract}

Keywords: 5-hydroxytryptamine, bone, osteoporosis

\section{INTRODUCTION}

5-hydroxytryptamin or serotonin represents a complex monoamine which is produced in brain and gut, mainly with different functions (1-3). Central production is related to neurotransmitters activities as mood, food and energy regulation (4-6). Brain serotonin is also linked to positive effects on bone mass (7-9). The other source of 5-hydroxytryptamine is gut-derived and it directly influences the skeleton having opposite skeleton actions to the central pool (10-12). That is why the circulating 5-hydroxytryptamine assays might not completely reflect what happens to the bone from the serotonin point of view $(13,14)$.

\section{MATERIAL AND METHOD}

This is a mini-review regarding serotonin- related bone changes. Most of the cited papers are accessed via Pub Med database of English written articles. 44 out of 50 references are from 2012 to 2016 , considering the novelty of the topic.

\section{RESULTS}

\section{Central 5-hydroxytryptamine}

Mouse models and later human research indentified a remodelling pathway control coming from central mainstream and involving 5-hydroxytryptamine (15-17). The link between brain and periphery is established not by central serotonin, that does not have the ability to cross the blood-brain barrier, but through leptin and sympathetic system (15-17). Brain serotonin, as neurotransmitter, communicates with others molecules involved in food intake and energy expenditure, like fat-derived adipokines. Thus, a loop of regulation between metabolic components as obesity and type 2 diabetes also in- 
cludes skeleton setup (18). A key player in this complex loop is leptin, which induces the proliferation of osteoblasts and their differentiation, blocking the cells apoptosis but controversies still exist (19). Leptin also modules the central sympathetic inputs to peripheral bone (19-21). The bone cortex is innervated by nerve fibers (regardless myelinated or not), while other innervations come from arterial and venous small vessels of the skeleton (20). These fibers provide the neural control of the bone (20). The most described system is sympathetic, while opposite parasympathetic bone influence is less described (21). A secondary frame of leptin intervention is related to osteocalcin $(22,23)$. Osteocalcin represents a molecule produced by the bone, serving an endocrine function of insulin sensitivity by inhibiting insulin producing pancreas cells and it also is a well known bone formation marker $(22,23)$. Osteocalcin and leptin inhibits each other based on a dual synergism $(22,23)$. Another element of interplay between food and energy pathways and skeleton regulation includes amylin with endocrine consequences over normal feeding process, while in vitro expresses anabolic bone actions (22-24). Murine experiments in ovarectomized rats revealed that 5-hydroxytryptamine is related to pain protection mechanisms which may be enhanced by administration of anti-osteoporotic drugs as calcitonin (through type 1 receptors of serotonin 5 -HTR1 located in thalamus) (25). The negative skeleton influence caused by central 5-hydroxytryptamine is tidily related to observations from large clinical studies on Selective Serotonine Reuptake Inhibitors (SSRI), which are drugs useful in depression interfering with a larger time frame of monoamine exposure (26-28). These aspects are confirmed in rats models, while in humans treated with SSRI the risk of osteoporotic fracture risk is displayed at any age, regardless females menopausal status (29-31). Young women with anorexia nervosa which involves a highly consumptive sta-

\section{Skeletal effects of 5-hydroxytryptamine}

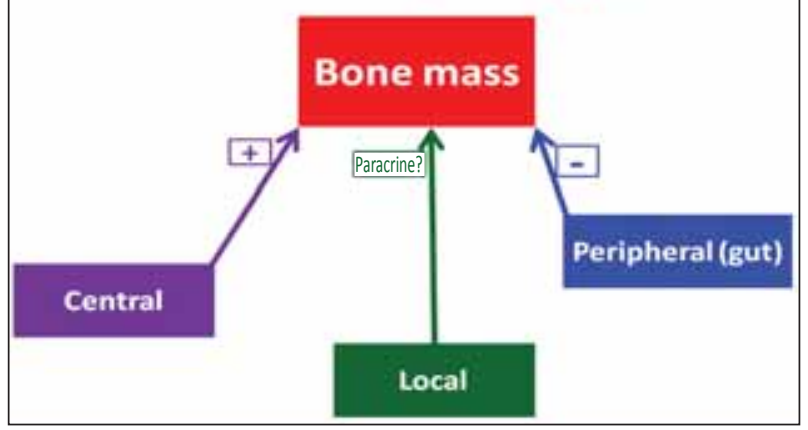

FIGURE 1. Skeletal effects of the 5-hydroxytryptamine (serotonin) tus associate low bone mineral density, as well as circulating serotonin and leptin while the balance between bone turnover markers is changed by increased bone resorption marker CTX and decreased bone formation marker osteocalcin (32).

\section{Peripheral 5-hydroxytryptamine}

Gut-produced 5-hydroxytryptamine is produced by tryptophan hydroxylase type 1 from tryptophan, the enzyme being located on enterochromaffin cells (33). Serotonin and its 24-hours urinary derivate 5-hydroxy-indol-acetic acid serves as classical neuroendocrine markers in different types of neuroendocrine tumors regardless entero-pancreatic or lung origin (34-36). Locally, serotonin is used for digestion and microbiome activity (37-39). From gut, 5-hydroxytryptamine goes into the platelets and then to different organs, but not into the brain (40). Intestinal 5-hydroxytryptamine uses the Wnt/ Lrp/beta catenin pathways to regulate skeleton health especially processes related to bone loss, opposite to central non-circulating serotonin which actually does not get directly at skeleton site (41). All the bone cells have receptors for serotonin (4244). Some studies indicate the intrinsic ability of skeleton to product local 5-hydroxytryptamine $(43,44)$. However the source, the monoamine displays local mechanisms at paracrine and autocrine level, which are still incompletely known up to these days $(43,44)$. Overall, the bone regulation is done by both circulating and central 5-hydroxytryptamine but, even they share the same biochemistry, they have antagonist effects (45).

\section{DISCUSSIONS}

One practical point directly linked to intestinal serotonin bone actions is the topic of potential bone mineral density damage in clinical situations with 5-hydroxytryptamine excess, as found in carcinoid tumors (46). Controversies in this topic exist and some studies pointed no correlation between circulating level and skeleton anomalies in non-bone metastatic neuroendocrine conditions (47). Others found a lower bone mineral density at hip level in patients with neuroendocrine neoplasia, even it is difficult to predict the associated fracture risk based on serotonin metabolites (48). Up to this moment, carcinoid syndrome - associated masses are not considered a cause of secondary osteoporosis (4648). Another practical aspect is the use of circulating 5-hydroxytryptamine as bone turnover marker surrogate for assessing the future fragility fracture 
probability $(49,50)$. Despite some correlations with classical bone remodelling markers, no clear cut conclusion has been established yet (50).

\section{CONCLUSION}

5-hydroxytryptamine displays complex effects on skeleton status, whether direct, indirect or local,

\section{REFERENCES}

1. Jenkins T.A., Nguyen J.C., Polglaze K.E., Bertrand P.P. Influence of Tryptophan and Serotonin on Mood and Cognition with a Possible Role of the Gut-Brain Axis. Nutrients. 2016 Jan 20;8(1). pii: E56. doi: 10.3390/nu8010056.

2. Michalowska M., Znorko B., Kaminski T., Oksztulska-Kolanek E., Pawlak D. New insights into tryptophan and its metabolites in the regulation of bone metabolism. J Physiol Pharmacol. 2015 Dec; 66(6):779-91.

3. Strasser B., Gostner J.M., Fuchs D. Mood, food, and cognition: role of tryptophan and serotonin. Curr Opin Clin Nutr Metab Care. 2016 Jan; 19(1):55-61.

4. Christensen L., Brooks A. Changing food preference as a function of mood. J Psychol. 2006 Jul; 140(4):293-306.

5. Meeusen R. Exercise and the brain: insight in new therapeutic modalities. Ann Transplant. 2005; 10(4):49-51.

6. Heisler L.K., Cowley M.A., Kishi T., et al. Central serotonin and melanocortin pathways regulating energy homeostasis. Ann N Y Acad Sci. 2003 Jun; 994:169-74.

7. Dimitri P., Rosen C. The Central Nervous System and Bone Metabolism: An Evolving Story. Calcif Tissue Int. 2016 Aug 8. [Epub ahead of print]

8. Worsaae K., Rimskaya-Korsakova N.N., Rouse G.W. Neural reconstruction of bone-eating Osedax spp. (Annelida) and evolution of the siboglinid nervous system. BMC Evol Biol. 2016 Apr 14; 16:83. doi: 10.1186/s12862-016-0639-7.

9. Bone Niedźwiedzki T., Filipowska J. Bone remodeling in the context of cellular and systemic regulation: the role of osteocytes and the nervous system. J Mol Endocrinol. 2015 Oct;55(2):R23-36. doi: 10.1530/JME-15-0067.

10. Kode A., Obri A., Paone R., et al. Lrp5 regulation of bone mass and serotonin synthesis in the gut. Nat Med. 2014 Nov;20(11):1228-9.

11. Kode A., Mosialou I., Silva B.C., et al. FOXO1 orchestrates the bone-suppressing function of gut-derived serotonin. ACJ Clin Invest. 2012 Oct; 122(10):3490-503.

12. Sjögren K., Engdahl C., Henning P., et al. The gut microbiota regulates bone mass in mice. J Bone Miner Res. 2012 Jun; 27(6):1357-67.

13. Kim M.K., Kwon H.S., Song K.H., Kang M.I., Baek K.H. The Relationship of Serum Serotonin Levels to the Rate of Bone Loss and Fractures in Men. J Clin Densitom. 2016 Sep 7. pii: S10946950(16)30113-5.

14. Carsote M., Radoi V., Geleriu A., et al. The serotonin and the bone assessment. J Med Life. 2013 Jun 15; 6(2):151-5.

15. Bliziotes M. Update in serotonin and bone. J Clin Endocrinol Metab. 2010 Sep; 95(9):4124-32.

16. Kawai M., Rosen C.J. Minireview: A skeleton in serotonin's closet? Endocrinology. 2010 Sep; 151(9):4103-8.

17. Zuo C., Huang Y., Bajis R., Sahih M., Li YP., Dai K., Zhang X. Osteoblastogenesis regulation signals in bone remodeling. Osteoporos Int. 2012 Jun; 23(6):1653-63.

18. Schwetz V., Pieber T., Obermayer-Pietsch B. The endocrine role of the skeleton: background and clinical evidence. Eur J Endocrinol. 2012 Jun; 166(6):959-67. but there are still various controversial or unknown data, thus the future need to connect the dots in this particular inter-disciplinary field.

Acknowledgement: This work has been partially supported by Carol Davila UMPh project 33878/11.11.2014/Young researchers.

19. Motyl K.J., Rosen C.J. Understanding leptin-dependent regulation of skeletal homeostasis. Biochimie. 2012 Oct; 94(10):2089-96.

20. Masi L. Crosstalk between the brain and bone. Clin Cases Miner Bone Metab. 2012 Jan; 9(1):13-6.

21. Bajayo A., Bar A., Denes A., et al. Skeletal parasympathetic innervation communicates central IL-1 signals regulating bone mass accrual. Proc Natl Acad Sci U S A. 2012 Sep 18; 109(38):15455-60.

22. D'Amelio P., Panico A., Spertino E., Isaia G.C. Energy metabolism and the skeleton: Reciprocal interplay. World J Orthop. 2012 Nov 18; 3(11):190-8.

23. Sharan K., Yadav V.K. Hypothalamic control of bone metabolism. Best Pract Res Clin Endocrinol Metab. 2014 Oct; 28(5):713-23.

24. Hay D.L., Chen S., Lutz T.A., Parkes D.G., Roth J.D. Amylin: Pharmacology, Physiology, and Clinical Potential. Pharmacol Rev. 2015 Jul; 67(3):564-600.

25. Yeh C.B., Weng S.J., Chang K.W., et al. Calcitonin alleviates hyperalgesia in osteoporotic rats by modulating serotonin transporter activity. Osteoporos Int. 2016 Jun 3. [Epub ahead of print]

26. Feuer A.J., Demmer R.T., Thai A., Vogiatzi M.G. Use of selective serotonin reuptake inhibitors and bone mass in adolescents: An NHANES study. Bone. 2015 Sep; 78:28-33.

27. Ak E., Bulut S.D., Bulut S., et al. Evaluation of the effect of selective serotonin reuptake inhibitors on bone mineral density: an observational cross-sectional study. Osteoporos Int. 2015 Jan; 26(1):273-9.

28. Calarge C.A., Butcher B.D., Burns T.L., et al. Major depressive disorder and bone mass in adolescents and young adults. J Bone Miner Res. 2014 Oct; 29(10):2230-7.

29. Diem S.J., Ruppert K., Cauley J.A., et al. Rates of bone loss among women initiating antidepressant medication use in midlife. J Clin Endocrinol Metab. 2013 Nov; 98(11):4355-63.

30. Calarge C.A., Zimmerman B., Xie D., Kuperman S., Schlechte J.A. A cross-sectional evaluation of the effect of risperidone and selective serotonin reuptake inhibitors on bonemineral density in boys. J Clin Psychiatry. 2010 Mar; 71(3):338-47.

31. Fekete S., Simko J., Mzik M., et al. Negative effect of serotoninnorepinephrine reuptake inhibitor therapy on rat bone tissue after orchidectomy. Eur J Pharmacol. 2015 Aug 15; 761:65-9.

32. Maïmoun L., Guillaume S., Lefebvre P., et al. Is Serum Serotonin Involved in the Bone Loss of Young Females with Anorexia Nervosa? Horm Metab Res. 2016 Mar; 48(3):174-7.

33. Palego L., Betti L., Rossi A., Giannaccini G. Tryptophan Biochemistry: Structural, Nutritional, Metabolic, and Medical Aspects in Humans. J Amino Acids. 2016; 2016:8952520. doi: 10.1155/2016/8952520. Epub 2016 Jan 12.

34. Carsote M., Paun S., Neamțu M.C., Avramescu E.T., losif C., Terzea D., Constantinoiu S., Dănciulescu Miulescu R., Neamțu O.M., Poiană C. The immunohistochemistry aspects in two cases of neurofibromatosis-associated abdominal tumors. Rom J Morphol Embryol. 2012; 53(2):401-5.

35. Poiana C., Neamțu M.C., Avramescu E.T., Carşote M., Trifănescu R., Terzea D., Neamțu O.M., Dănciulescu Miulescu R. The dedifferentiation of neuroendocrine tumor metastases: myth or reality? Rom J Morphol Embryol. 2013;54(1):201-3. 
36. Poiana C., Carşote M., Ardeleanu C., Terzea D., Avramescu E.T., Neamț M.C., Miulescu R.D. The value of the immunohistochemistry in a case of gastric neuroendocrine tumor and thyroid metastasis. Rom J Morphol Embryol. 2011; 52(1):187-92.

37. Young R.L., Lumsden A.L., Keating D.J. Gut Serotonin Is a Regulator of Obesity and Metabolism. Gastroenterology. $2015 \mathrm{Jul}$; 149(1):253-5.

38. Clarke G., Stilling R.M., Kennedy P.J., Stanton C., Cryan J.F., Dinan T.G. Minireview: Gut microbiota: the neglected endocrine organ. Mol Endocrinol. 2014 Aug; 28(8):1221-38.

39. Andoh A. Physiological Role of Gut Microbiota for Maintaining Human Health. Digestion. 2016; 93(3):176-81.

40. Warkentin T.E., Arnold D.M., Nazi I., Kelton J.G. The platelet serotonin-release assay. Am J Hematol. 2015 Jun; 90(6):564-72.

41. Johnson M.L. LRP5 and bone mass regulation: Where are we now? Bonekey Rep. 2012 Jan 10;1:1. doi: 10.1038/bonekey.2012.1. eCollection 2012.

42. Nam S.S., Lee J.C., Kim H.J., et al. Serotonin Inhibits Osteoblast Differentiation and Bone Regeneration in Rats. J Periodontol. 2016 Apr; 87(4):461-9.

43. de Vernejoul M.C., Collet C., Chabbi-Achengli Y. Serotonin: good or bad for bone. Bonekey Rep. 2012 Jul 4;1:120. doi: 10.1038/ bonekey.2012.120. eCollection 2012.
44. Amireault P., Sibon D., Côté F. Life without peripheral serotonin: insights from tryptophan hydroxylase 1 knockout mice reveal the existence of paracrine/autocrine serotonergic networks. ACS Chem Neurosci. 2013 Jan 16; 4(1):64-71.

45. Ducy P., Karsenty G. The two faces of serotonin in bone biology. J Cell Biol. 2010 Oct 4; 191(1):7-13. doi: 10.1083/jcb.201006123.

46. Poiana C., Carsote M., Neamtu M.C., et al. Well-differentiated neuroendocrine tumor and osteoporosis: incidental findings? Rom J Morphol Embryol. 2013; 54(4):1169-71.

47. Walsh J.S., Newell-Price J.D., DeBono M., Adaway J., Keevil B., Eastell R. Circulating serotonin and bone density, structure, and turnover in carcinoid syndrome. J Clin Endocrinol Metab. $2013 \mathrm{Jul}$; 98(7):2902-7.

48. Sen Gupta P., Grozinsky-Glasberg S., Drake W.M., Akker S.A., Perry L., Grossman A.B., Druce M.R. Are serotonin metabolite levels related to bone mineral density in patients with neuroendocrine tumours? Clin Endocrinol (Oxf). 2014 Feb; 80(2):246-52.

49. Lee G.S., Simpson C., Sun B.H., et al. Measurement of plasma, serum, and platelet serotonin in individuals with high bone mass and mutations in LRP5. J Bone Miner Res. 2014 Apr; 29(4):976-81.

50. Carsote M., Radoi V., Geleriu A., Mihai A., Ferechide D., Opris D., Paun D., Poiana C. The serotonin and the bone assessment. J Med Life. 2013 Jun 15; 6(2):151-5. 